\title{
Meta-analysis of the risk of mortality with salmeterol and the effect of concomitant inhaled corticosteroid therapy
}

\author{
M Weatherall, ${ }^{1,2} \mathrm{M}$ Wijesinghe, ${ }^{2,3} \mathrm{~K}$ Perrin, ${ }^{2,3} \mathrm{M}$ Harwood, ${ }^{3}$ R Beasley ${ }^{2,3,4}$
}

- Additional details are published online only at http:// thorax.bmj.com/content/vol65/ issue 1

${ }^{1}$ University of Otago Wellington, Wellington, New Zealand;

${ }^{2}$ Capital \& Coast District Health Board, Wellington, New Zealand; ${ }^{3}$ Medical Research Institute of New Zealand, Wellington, New Zealand;

${ }^{4}$ University of Southampton, Southampton, UK

Correspondence to: Professor R Beasley, Medical Research Institute of New Zealand, P 0 Box 10055 , Wellington 6143, New Zealand; richard.beasley@mrinz.ac.nz

Received 15 March 2009 Accepted 20 October 2009

\begin{abstract}
Background: There is concern that long-acting $\beta$ agonist (LABA) drugs may increase the risk of asthma mortality. Methods: A meta-analysis was conducted of asthma deaths in randomised controlled clinical trials from the GlaxoSmithKline database that compared salmeterol with a non-LABA comparator treatment in asthma. The Peto one-step method was used to determine the risk overall (all studies) and in derived datasets based on inhaled corticosteroid (ICS) use.
\end{abstract}

Results: There were 35 asthma deaths in 215 studies with 106575 subjects. Two studies (SMART and SNS) contributed $30 / 35(86 \%)$ asthma deaths, the overall findings largely reflecting the characteristics of these studies. The odds ratio for risk of asthma mortality with salmeterol was 2.7 (95\% Cl 1.4 to 5.3). In 54 placebo controlled studies the risk of death from asthma in patients not prescribed ICS was 7.3 (95\% Cl 1.8 to 29.4). In 127 studies in which patients were prescribed ICS, the risk of asthma death was 2.1 (95\% Cl 0.6 to 7.9). In 63 studies in which patients were randomised to receive the combination salmeterol/fluticasone propionate inhaler or ICS, there were no asthma deaths among 22600 patients.

Conclusions: Salmeterol monotherapy in asthma increases the risk of asthma mortality and this risk is reduced with concomitant ICS therapy. There is no evidence that combination salmeterol/fluticasone propionate therapy is associated with an increased risk of asthma mortality, although this interpretation is limited by the low statistical power of available studies.

The role of long-acting $\beta$ agonist (LABA) drugs in asthma mortality represents the latest chapter in a long running debate about the safety of inhaled $\beta$ agonist drugs in the treatment of asthma. ${ }^{1-10}$ Evidence for a possible increased risk of asthma mortality with LABA therapy was first raised in 1993 with publication of the Salmeterol Nationwide Surveillance Study (SNS). ${ }^{9}$ This study reported a statistically non-significant threefold increased risk of death in subjects treated with salmeterol compared with regular salbutamol, but no increase in hospital admissions or life-threatening events. These findings led to the Salmeterol Multicentre Asthma Research Trial (SMART), which reported a statistically significant fourfold increase in asthma mortality with salmeterol compared with placebo. ${ }^{10}$ In subgroup analyses, there was no increased risk in asthma mortality for salmeterol in subjects prescribed concomitant ICS therapy. Although limited by low power, this finding raised the possibility that the mortality risk was restricted to salmeterol as monotherapy and that concomitant use of ICS therapy may protect against the risk.

This interpretation was supported by the findings of the large UK-based case-control study in which there was no evidence of any positive association between LABAs and asthma death. ${ }^{11}$ As almost all patients in the UK during the period of the study who were prescribed LABA therapy were co-prescribed ICS therapy, ${ }^{12}$ these findings provided evidence that the use of LABAs with concomitant ICS therapy does not increase the risk of asthma mortality. ${ }^{13}$

To further investigate this issue we have undertaken a meta-analysis of all randomised controlled trials of salmeterol included in the GlaxoSmithKline (GSK) database to determine whether its use is associated with an increased risk of asthma mortality, and whether ICS therapy influences any such risk.

\section{METHODS}

The meta-analysis was undertaken on the GSK salmeterol safety database that was submitted to the FDA. The database included all published and unpublished chronic-dosing randomised controlled trials of salmeterol, funded or sponsored by GSK, completed by January 2008 (see online supplement).

\section{Inclusion criteria}

To be included in the meta-analysis, studies had to be randomised, double-blind, controlled, repeat dose, parallel group or crossover clinical trials that compared salmeterol (when used as a separate salmeterol or as a fixed dose combination salmeterol/fluticasone propionate inhaler) with a comparator non-LABA treatment in the management of asthma. Only the first period of crossover studies was included in the meta-analysis.

\section{Exclusion criteria}

Non-randomised, open label and single dose trials were excluded. Clinical pharmacology studies (pharmacokinetic or pharmacodynamic analyses), quality of life and pharmacoeconomic analyses and studies in which no comparator non-LABA treatment was examined (eg, studies in which formoterol was the sole comparator) were also excluded.

\section{Outcome measures}

The primary outcome variable was deaths due to asthma. Secondary outcomes were total deaths (all causes), admissions to hospital with asthma and asthma intubations (see online supplement). 
Figure 1 QUOROM figure showing studies included in the meta-analysis. GSK, GlaxoSmithKline; ICS, inhaled corticosteroids; LTRA, leukotriene receptor antagonist.

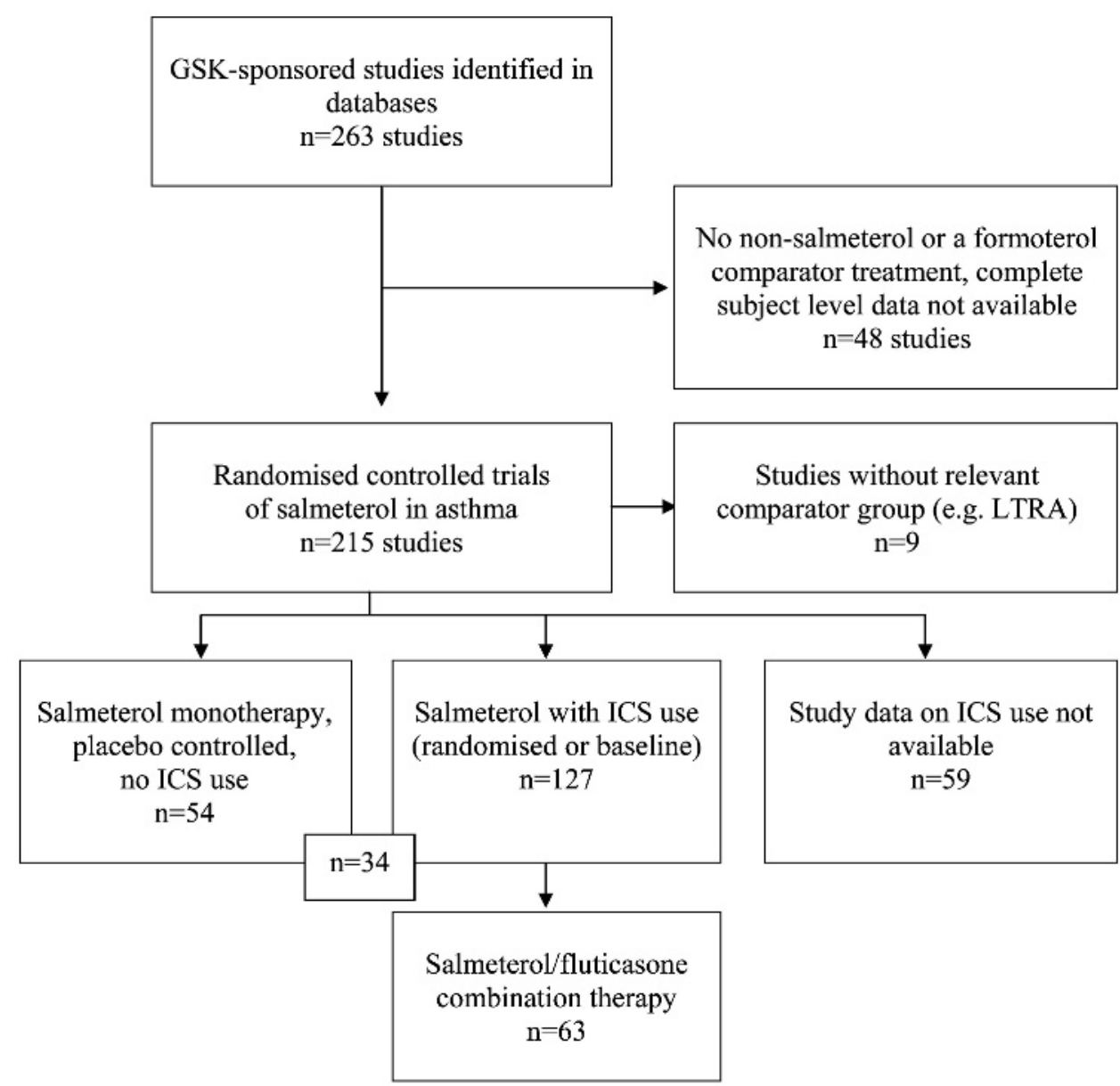

To assess the effect of salmeterol when used with concomitant ICS therapy, three datasets were derived based on information about ICS use. This approach was taken as not all the studies had individual participant information on ICS use, whereas most studies had aggregate information for the study as a whole.

- Salmeterol monotherapy: subjects randomised to salmeterol versus placebo in which subjects were not receiving ICS therapy as randomised or background therapy and ICS was not started during the course of the study.

- Salmeterol with ICS therapy: subjects randomised to salmeterol and also taking ICS (including ICS as randomised therapy or ICS as concurrent background medication at randomisation which was continued per protocol after randomisation, or ICS started during the period of the study) versus subjects receiving ICS (including ICS as randomised therapy or ICS as concurrent background medication at randomisation which was continued per protocol after randomisation, or ICS started during the period of the study).

- Salmeterol as combination salmeterol/fluticasone propionate therapy: subjects randomised to salmeterol via a combination salmeterol/fluticasone propionate (Advair/ Seretide) inhaler versus subjects randomised to an ICS.

Subjects from one study could be included in more than one ICS use group. For example, in the SMART study, ${ }^{10}$ subjects could be included in the salmeterol versus placebo comparison (Group 1: salmeterol monotherapy) and the salmeterol and ICS versus ICS comparison (Group 2: salmeterol with ICS therapy) if they were taking ICS as concurrent background medication.
Further subgroup analyses based, for example, on ethnic group, age, baseline asthma severity, dose, dose regime (once or twice daily), specific ICS or inhaler device were not attempted as we anticipated limited statistical power to detect associations with the small number of events within subgroups.

\section{Statistical methods}

Three statistical methods were used to determine the risk of mortality associated with salmeterol treatment (see online supplement). The primary method was the Peto's one-step odds ratio carried out according to the formulae given by Bradburn and colleagues. ${ }^{14}$ The second method was the simple contingency table odds ratio carried out by an exact method in SAS Version 9.1 using the "FREQ" procedure. For the third, the Bayesian method was implemented in WinBUGS 1.4 using the package "R2WinBUGS" in the $\mathrm{R}$ statistical programme. ${ }^{15}$

\section{RESULTS}

There were 263 studies included in the GSK clinical trial database of salmeterol (fig 1; see online supplement); 48 studies were excluded because there was no non-salmeterol comparator, formoterol was the comparator treatment or the data were incomplete. In one of the studies with incomplete data there was one asthma death in a patient who was randomised to treatment with salbutamol but not salmeterol. A total of 215 studies with 106575 randomised subjects and 39006 patientyears of treatment were therefore included in the full dataset. The number of subjects and total years of exposure to salmeterol and comparator treatment in the full dataset and 
in the patient groups based on ICS use are shown in table 1. There were 35 deaths from asthma included in the full dataset, of which $30(86 \%)$ came from two clinical trials, the SNS ${ }^{9}$ and SMART $^{10}$ (see online supplement).

\section{Overall analysis (all studies)}

There were 28/57 607 asthma deaths in subjects taking salmeterol and 7/48 968 in patients randomised to treatment with a non-LABA. The odds ratio for risk of asthma mortality associated with salmeterol was 2.7 (95\% CI 1.4 to 5.3) using the Peto method (table 2). A similar estimate of risk was observed with the simple contingency table method but not with the Bayesian method (see online supplement). The odds ratio for the risk of all-cause mortality associated with salmeterol was 1.3 (95\% CI 1.0 to 1.8 ) using the Peto method (table 2). A similar estimate of risk was observed with the simple contingency table method, but not with the Bayesian method (see online supplement). The odds ratio for risk of hospital admissions associated with salmeterol was 1.2 (95\% CI 1.1 to 1.4) using the Peto method. A similar estimate of risk was observed with both the simple contingency table method and the Bayesian method. The odds ratio for risk of intubations associated with salmeterol was 1.6 (95\% CI 1.0 to 2.5 ) using the Peto method. A similar estimate of risk was observed with the simple contingency table method but not with the Bayesian method.

\section{Salmeterol monotherapy}

There were 54 studies in which 18395 subjects received salmeterol or placebo as monotherapy, with no ICS as randomised or baseline prescribed therapy (table 3). There were eight deaths from asthma, all in the SMART study. ${ }^{10}$ This differs from the published study report, ${ }^{10}$ as one subject randomised to salmeterol who died was not taking ICS at baseline but received an ICS prescription some time during the study period and, as a result, was included in the "salmeterol with ICS therapy" comparison group. The odds ratio for the risk of asthma mortality was 7.3 (95\% CI 1.8 to 29.4) using the Peto method, although this is just the odds ratio for mortality for the single study (SMART) which accounted for all the asthma deaths in this analysis. It was not possible to calculate a risk from simple contingency tables or the Bayesian method. There was no statistically significant increased risk for all cause mortality or intubations. There was an increased risk of hospital admissions with an odds ratio of 1.4 (95\% CI 1.0 to 2.0$)$ by the Peto method. There were similar estimates of risk of hospital admissions with the single contingency table and Bayesian methods, but these were not significant.

\section{Salmeterol with ICS therapy (randomised and background)}

There were 127 studies in which 48715 subjects received ICS as randomised or baseline prescribed therapy (table 4). There were nine deaths from asthma, eight of which came from the SMART study. ${ }^{10}$ The odds ratio for the risk of asthma mortality was 2.1 (95\% CI 0.6 to 7.9) using the Peto method. A similar estimate of risk was obtained from the single contingency table method and it was not possible to calculate a risk with the Bayesian method due to convergence problems (see online supplement). There was no statistically significant increased risk for all-cause mortality or intubations. There was an increased risk of hospitalisations, with an odds ratio of 1.3 (95\% CI 1.1 to 1.5 ) by the Peto method.

\section{Salmeterol as combination salmeterol/fluticasone propionate therapy}

There were 63 studies with 22600 subjects in whom the combination salmeterol/fluticasone propionate inhaler was compared with ICS therapy (table 5). There were no deaths from asthma so it was not possible to calculate a risk of asthma mortality. There was no statistically significant risk of all-cause mortality and no events on which to calculate a risk of intubations. There was no increased risk of hospitalisations by any of the analytical methods used (see online supplement).

\section{DISCUSSION}

The findings from these meta-analyses suggest that salmeterol as monotherapy in poorly controlled asthma increases the risk of asthma mortality, and that this risk is reduced with concomitant ICS therapy. There is no evidence to suggest that combination salmeterol/fluticasone propionate therapy is associated with an increased risk of asthma mortality, although this interpretation is limited by the low statistical power of available studies to detect important differences in asthma mortality.

Meta-analysis of trials with rare outcome measures is problematic and three methods of statistical analyses were undertaken. Peto's one-step odds ratio was the primary method of analysis as it performs best under certain conditions in the meta-analysis of trials with rare events. ${ }^{14}$ These conditionswhich include event rates $<1 \%$, no substantial imbalance between control and treatment group sizes within trials and treatment effects not particularly large-were met for the trials included in the meta-analysis. However, the Peto method can only use information from those trials with at least one event in one arm of the trial to calculate a relative risk and ignores information on the length of the trial. A secondary method of analysis was the single two-by-two table of events which treats all trials as one large trial and may be applicable if the trials have

Table 1 Summary of exposure by population

\begin{tabular}{|c|c|c|c|c|c|}
\hline \multirow[b]{2}{*}{ Population } & \multirow[b]{2}{*}{$\begin{array}{l}\text { No of } \\
\text { studies }\end{array}$} & \multicolumn{2}{|c|}{$\begin{array}{l}\text { Salmeterol-containing } \\
\text { product }\end{array}$} & \multicolumn{2}{|c|}{ Comparator } \\
\hline & & $\begin{array}{l}\text { No of } \\
\text { subjects }\end{array}$ & $\begin{array}{l}\text { Total exposure } \\
\text { (years) }\end{array}$ & $\begin{array}{l}\text { No of } \\
\text { subjects }\end{array}$ & $\begin{array}{l}\text { Total } \\
\text { exposure } \\
\text { (years) }\end{array}$ \\
\hline Salmeterol-containing product vs non-LABA & 215 & 57607 & 20573 & 48968 & 18433 \\
\hline Salmeterol vs placebo (without ICS) & 54 & 9463 & 3787 & 8932 & 3682 \\
\hline Salmeterol + ICS (BK/RD)* vs ICS (BK/RD)* & 127 & 24542 & 10285 & 24173 & 10243 \\
\hline $\begin{array}{l}\text { Fluticasone/salmeterol combination }(\mathrm{RD}) \dagger \text { vs ICS } \\
(\mathrm{RD}) \dagger\end{array}$ & 63 & 11437 & 5020 & 11163 & 5008 \\
\hline
\end{tabular}

${ }^{*} \mathrm{BK} / \mathrm{RD}$, ICS received as background medication or as randomised study drug.

$\uparrow R D$, ICS received as randomised study drug.

ICS, inhaled corticosteroid; LABA, long-acting $\beta$ agonist. 
Table 2 Odds ratio for risk of death and other outcomes associated with salmeterol treatment: any salmeterol versus non-LABA (215 studies)

\begin{tabular}{|c|c|c|c|}
\hline \multicolumn{4}{|c|}{ Primary analyses: Peto method } \\
\hline \multirow[b]{2}{*}{ Outcome } & \multirow{2}{*}{$\begin{array}{l}\text { No of studies } \\
\text { with data }\end{array}$} & \multicolumn{2}{|c|}{ Odds ratio $(95 \% \mathrm{CI})$} \\
\hline & & Fixed effect & Random effects \\
\hline Asthma deaths & 7 & $2.7(1.4$ to 5.3$)$ & $2.6(1.1$ to 5.9$)$ \\
\hline All deaths & 15 & $1.3(1.0$ to 1.8$)$ & $1.3(1.0$ to 1.8$)$ \\
\hline Hospitalisations & 104 & $1.2(1.1$ to 1.4$)$ & $1.4(1.1$ to 1.7$)$ \\
\hline Intubations & 14 & $1.6(1.0$ to 2.5$)$ & $1.6(0.9$ to 2.8$)$ \\
\hline
\end{tabular}

similar clinical samples and designs, but ignores the heterogeneity of the trials. The Bayesian approach has the advantage that it can use the information from trials with no event in either arm to contribute to an overall estimate of event rate and can also incorporate information about the different length of follow-up. However, even this method was problematic owing to the sparse data, with failure of the numerical implementation to converge on estimates in some of the analyses.

A key issue is that the SNS ${ }^{9}$ and SMART ${ }^{10}$ studies contributed $86 \%$ of all asthma deaths and, as a result, the findings for the full database predominantly relate to the clinical practice that applied within these studies. The SNS was undertaken almost 20 years ago, with about one in three patients in the study not receiving ICS therapy, and combination salmeterol/fluticasone propionate inhaler therapy was not available. In the SMART study just over half of the patients did not receive concomitant ICS therapy despite having unstable asthma. The SMART study contributed all eight deaths to the database in which salmeterol was prescribed as monotherapy, from which a 7.3fold increased risk of mortality was identified. Based on this analysis, one of our main findings is that the use of salmeterol without concomitant ICS therapy in unstable asthma increases the risk of death from asthma.

The next issue is whether there is a risk of asthma mortality with salmeterol when used in association with ICS. When analyses were restricted to this management approach there were only nine asthma deaths in more than 48000 subjects, with eight of the deaths coming from the SMART study. While the lack of a statistically significant increase in asthma mortality with salmeterol and ICS therapy provides some reassurance, the analysis lacked statistical power to rule out important associations. This interpretation is consistent with that of the recent Cochrane review ${ }^{16}$ in which unpublished SNS data were obtained from GSK on the use of ICS at baseline for each of the asthma-related deaths and the proportion of subjects taking baseline ICS. This enabled a combined analysis of the risk of asthma mortality with salmeterol in association with ICS use from the SNS and SMART studies. In the subgroup taking ICS at baseline the increase in asthma mortality was small and not statistically significant but associated with wide confidence intervals (odds ratio 1.49 , 95\% CI 0.54 to 4.11).

In considering the potential influence of concomitant ICS therapy on the risk of asthma mortality, there are likely to be differences in risk depending on the form in which they are prescribed. In standard clinical practice, compliance with ICS is poor, with patients taking on average no more than half of all prescribed doses. ${ }^{17} 18$ As a result, many patients prescribed LABAs with ICS will be taking LABA as monotherapy for variable periods of time. The only way in which it can be ensured that patients cannot take LABA as monotherapy is through their prescription as a combination LABA/ICS inhaler.
Table 3 Odds ratio for risk of death and other outcomes associated with salmeterol treatment: salmeterol versus placebo (54 studies)

\begin{tabular}{|c|c|c|c|}
\hline \multicolumn{4}{|c|}{ Primary analyses: Peto method } \\
\hline \multirow[b]{2}{*}{ Outcome } & \multirow{2}{*}{$\begin{array}{l}\text { No of studies } \\
\text { with data }\end{array}$} & \multicolumn{2}{|c|}{ Odds ratio $(95 \% \mathrm{Cl})$} \\
\hline & & Fixed effect & Random effects \\
\hline Asthma deaths & 1 & $7.3(1.8$ to 29.4$)$ & NA \\
\hline All deaths & 2 & $1.1(0.6$ to 2.0$)$ & $1.1(0.5$ to 2.3$)$ \\
\hline Hospitalisations & 23 & $1.4(1.0$ to 2.0$)$ & $1.4(1.0$ to 2.0$)$ \\
\hline Intubations & 4 & $1.5(0.7$ to 3.3$)$ & $1.4(0.4$ to 4.9$)$ \\
\hline
\end{tabular}

When the analysis was restricted to the 63 studies in which the combination salmeterol/fluticasone propionate product was used, there were no asthma deaths or intubations and no increase in risk of hospital admissions for asthma. As a result, there is no evidence from this meta-analysis that combination salmeterol/fluticasone propionate therapy influences the risk of asthma death, life-threatening attacks or hospital admissions, with the proviso that this interpretation is limited by the low power from available studies.

This systematic review and meta-analysis did not address the potential mechanisms whereby salmeterol may influence the risk of asthma mortality in certain circumstances. The longterm use of salmeterol has the potential to reduce bronchodilator sensitivity to $\beta$ agonists ${ }^{19}$ and to induce tolerance to their bronchoprotective effects ${ }^{20}$ which may not be restored by concurrent use of ICS. ${ }^{21}$ Patients using salmeterol may also be at potential risk of severe exacerbations if the symptom control achieved with salmeterol leads to a discontinuation of ICS therapy. Conversely, salmeterol in the form of a combination salmeterol/fluticasone propionate product may increase compliance with $\mathrm{ICS}^{22}{ }^{23}$ and, for this reason, have the potential to reduce the risk owing to the dose-dependent reduction in asthma mortality associated with ICS therapy. ${ }^{24}$ At the population level, combination LABA/ICS products also have the potential to reduce the risk of asthma mortality if the strong patient and doctor preference for this therapeutic approach leads to a greater overall use of ICS therapy than would otherwise have occurred. This issue cannot be addressed by randomised controlled trials as it relates to patterns of prescribing. However, observational data suggest that the widespread use of LABAs in the form of combination LABA/ ICS therapy may have led to a reduction in asthma mortality through the greater prescription of ICS. ${ }^{13} 2526$

It is informative to compare our findings with those of the recent meta-analysis of formoterol based on the AstraZeneca database. ${ }^{27}$ When a comparable statistical approach was used with analyses restricted to studies with a non-LABA comparator, the risk of asthma mortality associated with formoterol was 2.53 (95\% CI 0.45 to 26.0$).{ }^{28}$ In patients prescribed ICS the risk

Table 4 Odds ratio for risk of death and other outcomes associated with salmeterol treatment: salmeterol/ICS (randomised or background) versus ICS (randomised or background) (127 studies)

\begin{tabular}{llll}
\hline Primary analyses: Peto method & & \\
\hline & $\begin{array}{l}\text { No of studies } \\
\text { with data }\end{array}$ & \multicolumn{2}{l}{ Odds ratio (95\% CI) } \\
\cline { 3 - 4 } Outcome & 2 & $2.1(0.6$ to 7.9$)$ & $2.2(0.5$ to 9.3$)$ \\
\hline Asthma deaths & 8 & $1.5(0.8$ to 2.7$)$ & $1.5(0.8$ to 2.7$)$ \\
All deaths & 55 & $1.3(1.1$ to 1.5$)$ & $1.4(1.1$ to 1.8$)$ \\
Hospitalisations & 6 & $1.7(0.9$ to 3.4$)$ & $1.7(0.9$ to 3.4$)$ \\
Intubations & 6 & &
\end{tabular}


Table 5 Odds ratio for risk of death and other outcomes associated with salmeterol treatment: Advair versus ICS (as study drug) (63 studies)

\begin{tabular}{lcll}
\hline Primary analyses: Peto method & & \\
\hline & \multirow{2}{*}{$\begin{array}{l}\text { No of studies } \\
\text { With data }\end{array}$} & \multicolumn{2}{l}{ Odds ratio $\mathbf{9 5 \%} \mathbf{~ C l})$} \\
\cline { 3 - 4 } & Fixed effect & Random effects \\
\hline Asthma deaths & 0 & NA & NA \\
All deaths & 4 & $0.6(0.2$ to 2.4$)$ & $0.6(0.2$ to 2.4$)$ \\
Hospitalisations & 20 & $1.0(0.6$ to 1.7$)$ & $1.0(0.6$ to 1.7$)$ \\
Intubations & 0 & NA & NA \\
\hline
\end{tabular}

of asthma mortality with formoterol was 3.67 (95\% CI 0.41 to 174.0). ${ }^{28}$ While it is difficult to compare the salmeterol and formoterol findings, different patterns appear to exist with the risk with salmeterol being reduced with concomitant ICS therapy but not with formoterol. It will be important to determine the extent to which these different patterns of risk might be driven by the "as required" use of formoterol in the studies in which formoterol was co-prescribed with ICS therapy. This regime inherently carries a risk of overuse in the situation of a severe attack. Further evidence to suggest that a difference in risk may exist between salmeterol and formoterol when combined with ICS therapy comes from the recent FDA meta-analysis. ${ }^{29}$ From patient level data in 110 randomised placebo controlled trials of LABAs in asthma, the risk of composite asthma-related death, intubation or hospitalisation was 7.49 events per 1000 subjects ( $95 \%$ CI -1.47 to 16.44 ) with Symbicort (combination formoterol/budesonide inhaler) and -0.15 events per 1000 subjects ( $95 \%$ CI -2.01 to 1.70 ) with Advair (salmeterol/fluticasone propionate).

It is also relevant to consider the case-control studies of LABA therapy and near fatal and/or fatal attacks of asthma which have reported no statistically significant increased risk after adjusting for confounding variables. ${ }^{11}$ 30-33 The most important of these was the large UK-based study in which there was no evidence of any positive association between LABAs and asthma. ${ }^{11}$ However, most of these studies have low power and report upper confidence limits that would support an increased risk of asthma death and/or life-threatening attacks. ${ }^{30-33}$

In conclusion, we suggest that the potential risk of asthma mortality associated with the LABAs salmeterol and formoterol requires further investigation. The priority is to investigate the risk with combination LABA/ICS therapy, the preferred LABA product which represents the only form in which the prescriber can be certain that LABAs are not used as monotherapy. Different regimes would need to be assessed to determine whether the risk is influenced by patterns of LABA use, particularly variable dose regimes. In addition to large randomised controlled trials, case-control studies would also be informative in the investigation of the risk of such a rare outcome as mortality. ${ }^{34}$

Acknowledgements: The authors thank GSK for providing the salmeterol clinical trials safety database for independent analysis.

Funding: The study was funded by a grant of NZ\$24 000 from MedSafe, New Zealand Ministry of Health. MW is a Wellington Hospitals and Health Foundation Research Fellow and KP is a Health Research Council of New Zealand Training Fellow. The study sponsors had no role in study design, data collection, analysis, data interpretation, writing of the report or in the decision to submit the paper for publication.

Competing interests: The Medical Research Institute of New Zealand has received research grants from AstraZeneca, GlaxoSmithKline and Novartis. RB has received fees for consulting and speaking and reimbursement for attending symposia from AstraZeneca, GlaxoSmithKline and Novartis. All other authors have no conflict of interest.

Provenance and peer review: Not commissioned; externally peer reviewed.

\section{REFERENCES}

1. Lowell FC, Curry JJ, Schiller IW. A clinical and experimental study of isoprel in spontaneous and induced asthma. N Engl J Med 1949:240:45-51.

2. Van Metre TE. Adverse effects of inhalation of excessive amounts of nebulised isoproterenol in status asthmaticus. J Allergy 1969;43:101-13.

3. Stolley PD. Why the United States was spared an epidemic of deaths due to asthma. Am Rev Respir Dis 1972;105:883-90.

4. Crane J, Pearce N, Flatt A, et al. Prescribed fenoterol and death from asthma in New Zealand, 1981-83: a case control study. Lancet 1989:1:917-22.

5. Spitzer WO, Suissa S, Ernst P, et al. The use of beta-agonists and the risk of death and near death from asthma. N Engl J Med 1992:326:501-6.

6. Martinez FD. Safety of long-acting beta-agonists - an urgent need to clear the air. N Engl J Med 2005;353:2637-9.

7. Salpeter SR, Buckley NS, Orniston TM, et al. Meta-analysis: effect of long-acting beta-agonists on severe asthma exacerbations and asthma-related deaths. Ann Intern Med 2006; 144:904-12.

8. Hasford J, Virchow JC. Excess mortality in patients with asthma on long-acting $\beta_{2}$ agonists. Eur Respir J 2006;28:900-2.

9. Castle W, Fuller R, Hall J, et al. Serevent Nationwide Surveillance Study: comparison of salmeterol with salbutamol in asthmatic patients who require regular bronchodilator treatment. BMJ 1993;306:1034-7.

10. Nelson HS, Weiss ST, Bleecker ER, et al. The Salmeterol Multicenter Asthma Research Trial: a comparison of usual pharmacotherapy for asthma or usual pharmacotherapy plus salmeterol. Chest 2006;129:15-26.

11. Anderson HR, Ayres JG, Sturdy PM, et al, for the Mortality and Severe Morbidity Group of the National Asthma Task Force. Bronchodilator treatment and deaths from asthma: case-control study. BMJ 2005;330:117.

12. Maringe C, Rickard K, DiSantostefano R, et al. Concomitant use of long-acting betaagonists with inhaled corticosteroids among asthma patients in the UK primary care (abstract). Paper presented at European Respiratory Society Annual Congress, 2007.

13. Wijesinghe M, Perrin K, Harwood M, et al. The risk of asthma mortality with inhaled long acting $\beta$-agonists. Postgrad Med J 2008;84:467-72.

14. Bradburn MJ, Deeks JJ, Berlin JA, et al. Much ado about nothing: a comparison of the performance of meta-analytical methods with rare events. Stat Med 2007;26:53-77.

15. Gelman A, Carlin JB, Stern HS, et al. Bayesian statistical analysis. 2nd ed. Chapman and Hall/CRC, Boca Raton, 2004.

16. Cates CJ, Cates MJ. Regular treatment with salmeterol for chronic asthma: serious adverse events (review). The Cochrane Library 2009;(2). http://www. thecochranelibrary.com

17. Williams LK, Pladevall M, Hugo $X$, et al. Relationship between adherence to inhaled corticosteroids and poor outcomes among adults with asthma. J Allergy Clin Immunol 2004;114:1288-93

18. Krishnan JA, Riekert KA, McCoy JV, et al. Corticosteroid use after hospital discharge among high-risk adult with asthma. Am J Respir Crit Care Med 2004:170:1281-5.

19. Grove A, Lipworth BJ. Bronchodilator subsensitivity to salbutamol after twice daily salmeterol in asthmatic patients. Lancet 1995;346:201-6.

20. Cheung D, Timmers MC, Zwinderman AH, et al. Long-term effects of a long-acting $\beta_{2}$-adrenoceptor agonist, salmeterol, on airway hyperresponsiveness in patients with mild asthma. N Engl J Med 1992;327:1198-203.

21. Yates DH, Kharitonov SA, Barnes PJ. An inhaled glucocorticoid does not prevent tolerance to the bronchoprotective effect of a long-acting $\beta_{2}$-agonist. Am J Respir Crit Care Med 1996:154:1603-7.

22. Stoloff SW, Stempel DA, Meyer J, et al. Improved refill persistence with fluticasone propionate and salmeterol in a single inhaler compared with other controller therapies. J Allergy Clin Immunol 2004:113:245-51.

23. Stempel DA, Stoloff SW, Carranza Rosenzweig JR, et al. Adherence to asthma controller medication regimens. Respir Med 2005;99:1263-7.

24. Suissa S, Ernst P, Benayoun S, et al. Low-dose inhaled corticosteroids and the prevention of death from asthma. N Engl J Med 2000;343:332-6.

25. DiSantostefano RL, Davis KJ, Yancey S, et al. Ecologic analysis of asthma-related events and dispensing of inhaled corticosteroid- and salmeterol-containing products. Ann Allergy Asthma Immunol 2008; 100:558-65.

26. Wijesinghe $\mathbf{M}$, Weatherall $\mathrm{M}$, Perrin $\mathrm{K}$, et al. International trends in asthma mortality rates in the 5-34 year age group: a call for closer surveillance. Chest 2009;135:1045-9.

27. Sears MR, Ottosson A, Radner $F$, et al. Long-acting $\beta$-agonists: a review of formoterol safety data from asthma clinical trials. Eur Respir J 2009:33:21-32.

28. Beasley R, Martinez F, Hackshaw A, et al. Safety of long-acting beta agonists: urgent need to clear the air remains. Eur Respir J 2009;33:3-5.

29. Kramer JM. Balancing the benefits and risks of inhaled long-acting beta-agonists the influence of values. N Engl J Med 2009;360:1592-5.

30. Williams C, Crossland L, Finnerty J, et al. Case-control study of salmeterol and nearfatal attacks of asthma. Thorax 1998;53:7-13.

31. Lanes SF, Garcia Rodriguez LA, Hueta C. Respiratory medications and risk of asthma death. Thorax 2002:57:683-6.

32. Lanes SF, Lanza LL, Wentworth III CE. Risk of emergency care, hospitalization, and ICU stays for acute asthma among recipients of salmeterol. Am J Respir Crit Care Med 1998;158:857-61.

33. Meier $\mathbf{C R}$, Jick $\mathrm{H}$. Drug use and pulmonary death rates in increasingly symptomatic asthma patients in the UK. Thorax 1997:52:612-7.

34. Pearce NE, Crane J. Epidemiological methods for studying the role of beta receptor agonist therapy in asthma mortality. In: Beasley R, Pearce NE, eds. The role of beta agonist therapy in asthma mortality. New York: CRC Press, 1993:68-83. 